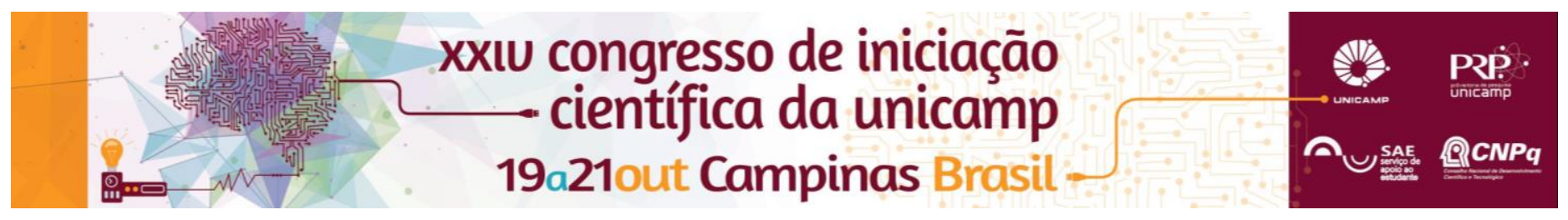

\title{
Automação de aquários usando Arduino para experimentação remota.
}

\section{Rodrigo Ferla*, Eduardo Galembeck.}

\section{Resumo}

A experimentação remota consiste em uma ferramenta que torna possível a interação entre internet e o mundo físico, ou seja, um experimento real, com instrumentos laboratoriais e equipamentos que podem ser controlados pelo computador através da internet. Sendo assim esse projeto tem por objetivo a automação de aquários que disponibilizarão para alunos - recursos, de forma remota - muitas vezes indisponíveis nos seus ambientes de estudo.

\section{Palavras-chave:}

Automação de aquários, experimentação remota, Arduino.

\section{Introdução}

A experimentação remota possibilita a estudantes acesso a recursos muitas vezes indisponíveis em seu ambiente de estudo. Esta ferramenta transforma um computador ou um smartphone em um laboratório móvel, permitindo a realização de experimentos práticos a qualquer momento e em qualquer lugar. Neste sentido, esse projeto objetivou desenvolver um sistema automatizado para monitoramento e controle de tanques de cultura de microrganismos de vida livre, para a realização de experimentos que envolvem o estudo da influência de fatores ambientais como $\mathrm{pH}$, temperatura, concentração de oxigênio dissolvido e luminosidade em ambientes aquáticos.

\section{Resultados e Discussão}

A Figura 1 se trata do protótipo do sistema automatizado usando um microcontrolador Arduino ${ }^{1}$. O sistema é composto por dois aquários e métodos que são controlados pelo Arduino.

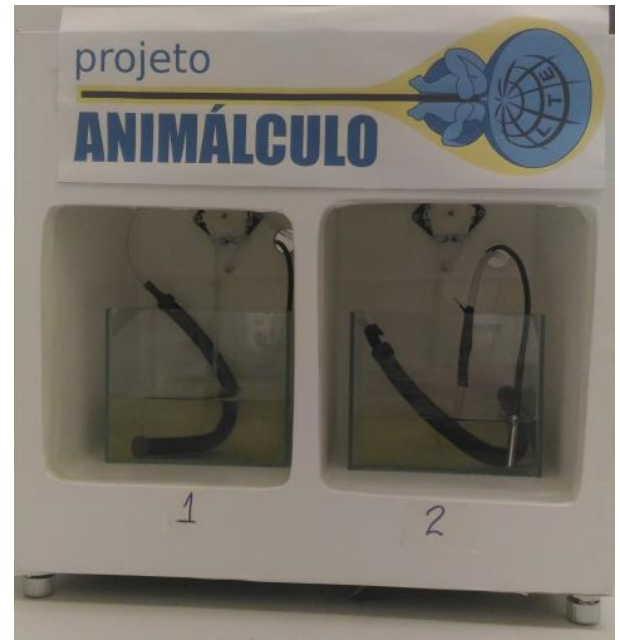

Figura 1. Protótipo da automação dos aquários.

Os métodos são responsáveis pelo controle e monitoramento do sistema, são eles: dosadores peristálticos, termômetros, ventoinhas, sensores de luminosidade, sensores de $\mathrm{pH}$ e oxigênio dissolvido, bombas de oxigênio, placas térmicas e LEDs. Para o devido monitoramento dos aquários dados relevantes, tais como: temperatura, oxigênio dissolvido, $\mathrm{pH}$ e intensidade luminosa são armazenados em um banco de DOI: 10.19146/pibic-2016-51984 dados e convertidos em um gráfico dinâmico, permitindo assim que os usuários acompanhem as mudanças desses fatores durante o período de experimento e correlacionem com 0 que acontece com os microrganismos nos aquários.

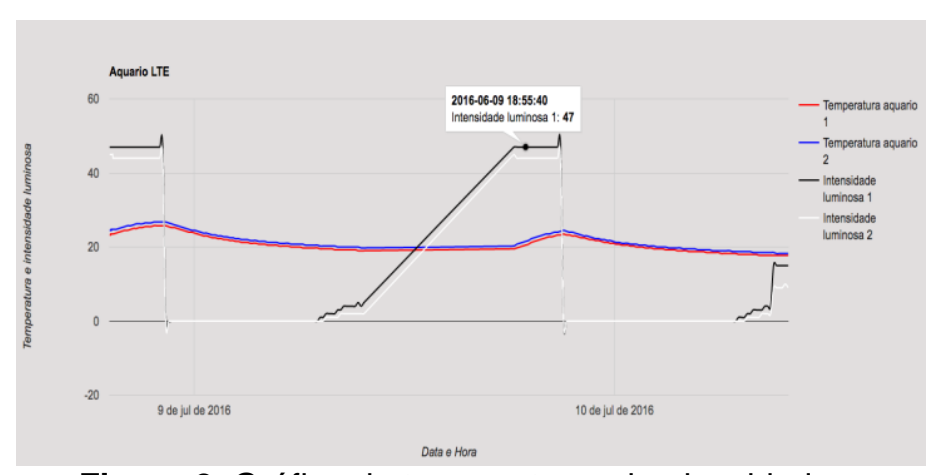

Figura 2. Gráfico da temperatura e luminosidade.

A Figura 2 mostra o gráfico da temperatura e da luminosidade no aquário durante dois dias de teste. Isso nos permite durante um experimento, por exemplo, observar a influencia da luminosidade e da temperatura nos microrganismos existentes nos tanques.

\section{Conclusões}

A experimentação remota traz uma gama de oportunidades para alunos que não tem acesso a um laboratório em sua escola, nesse projeto tornamos possível que alunos estudem culturas de microrganismos e analisem sua forma de vida sob vários fatores ambientais controlados de forma remota.

\section{Agradecimentos}

Conselho Nacional de Desenvolvimento Científico e Tecnológico (CNPq).

${ }^{1}$ Disponível em: < https://www.arduino.cc/en/Guide/HomePage $>$, Acesso em: 03/07/2016 